\title{
Relationship between serum calcium level at dialysis initiation and subsequent prognosis
}

Daijo Inaguma*, Shigehisa Koide, Kazuo Takahashi, Hiroki Hayashi, Midori Hasegawa, Yukio Yuzawa and For the Aichi Cohort Study of Prognosis in Patients Newly Initiated Into Dialysis (AICOPP)

\begin{abstract}
Background: In patients on maintenance dialysis, increased serum calcium levels are known to be associated with a poor prognosis. However, it is not known whether serum calcium levels at dialysis initiation have an impact on subsequent prognosis.

Methods: The subjects were patients who were newly initiated dialysis at the 17 Aichi Cohort Study of Prognosis in Patients Newly Initiated into Dialysis (AICOPP) group centers. The study included 1524 patients who were at least 20 years old, had CKD, and provided written consent. We excluded one patient whose serum adjusted calcium was not assessed and six patients whose outcomes were unknown. Thus, we enrolled 1517 subjects into the study. The patients were divided into the following five groups: (1) G1 with a serum adjusted calcium level $<7.0 \mathrm{mg} / \mathrm{dL}$, (2) G2 with 7.0 to $<8.0 \mathrm{mg} / \mathrm{dL}$, (3) G3 with 8.0 to $<9.0 \mathrm{mg} / \mathrm{dL}$, (4) G4 with 9.0 to $<10.0 \mathrm{mg} / \mathrm{dL}$, and (5) G5 with $\geq 10.0 \mathrm{mg} / \mathrm{dL}$. The study outcomes included: (1) comparisons of all-cause mortality rates in the five groups; (2) extraction of factors influencing all-cause mortality.
\end{abstract}

Results: There were 268 deaths during the follow-up period (G1, 9 cases; G2, 30 cases; G3, 91 cases; G4, 110 cases; G5, 28 cases). Significant differences were observed between the five groups' cumulative survival rates (Logrank test $p=0.005)$ by using Kaplan-Meier method. There were significant differences in the incidence of either aortic or cardiac valve calcification among the five groups (aortic calcification: $p=0.006$, cardiac valve calcification: $p=0.008$ ). Moreover, lower Barthel Index, which evaluated activities of daily living, were associated with higher serum adjusted calcium levels $(p<0.001)$. Multivariate Cox proportional hazard analysis using the stepwise method indicated that increasing serum adjusted calcium was associated with all-cause mortality (every $1 \mathrm{mg} / \mathrm{dL}$ increase, $\mathrm{HR}=1.267,95 \% \mathrm{Cl}=1.092-1.470, p=0.002$ ). In addition, high mortality was associated with advanced age, male gender, low systolic blood pressure, history of cardiovascular disease, and no prior use of calcium carbonate.

Conclusions: Serum adjusted calcium levels at dialysis initiation were demonstrated to be associated with all-cause mortality after dialysis initiation.

Trial registration: UMIN 000007096. Registered 18 January 2012.

Keywords: Dialysis initiation, Serum calcium, All-cause mortality, Chronic kidney disease

\footnotetext{
* Correspondence: daijo@fujita-hu.ac.jp

Department of Nephrology, Fujita Health University, Toyoake, Aichi, Japan
} 


\section{Background}

In patients newly starting dialysis, advanced age and concurrent cardiovascular diseases (CVDs) are major problems which are strongly associated with survival prognosis. The concept of chronic kidney diseasemineral and bone disorders (CKD-MBD) focuses on survival prognosis rather than bone lesions, and management of serum phosphorus and calcium levels is considered to be especially important [1]. In patients on dialysis, serum phosphorus levels have been shown to have a U-shaped association with mortality [2-7]. As for serum calcium levels, although it is not clear whether low levels are detrimental, high levels are known to be associated with a poor prognosis [3, 4, 8]. Given these background conditions, each guideline provides target values for serum phosphorus and calcium levels when managing patients on dialysis $[1,9]$.

Increased serum calcium levels reportedly cause vascular calcification and carry a risk of CVD [10-12]. However, serum calcium levels often tend to decrease during the predialysis stage of CKD including the period immediately before dialysis initiation [13]. Although secondary hyperparathyroidism has already manifested in this stage, it rarely progresses to nodular hyperplasia and is unlikely to cause hypercalcemia. Doi et al. documented a serum calcium level $>8.5 \mathrm{mg} / \mathrm{dL}$ at dialysis initiation to be associated with outcomes at one year after dialysis initiation [14], but only a few other reports have described similar findings. Whether the association observed in patients on maintenance dialysis between serum calcium levels and survival prognosis is also present in patients starting dialysis merits investigation.

Thus, the present study aimed to elucidate the association between serum calcium levels at dialysis initiation and subsequent prognosis.

\section{Methods \\ Subjects}

The subjects were patients who were newly initiated dialysis at the 17 Aichi Cohort Study of Prognosis in Patients Newly Initiated into Dialysis (AICOPP) group centers from October 2011 to September 2013 [15]. Patients who were withdrawn from dialysis while hospitalized, died while hospitalized, or did not agree to be registered were excluded. The study included 1524 patients who were at least 20 years old, had CKD, and provided written consent. We excluded one patient whose serum adjusted calcium was not assessed and six patients whose outcomes were unknown, as determined by a survey conducted at the end of March 2015. Thus, we enrolled 1517 subjects into the study.
Patient characteristics and data when dialysis was initiated (baseline)

Body mass index (BMI) was measured at the first dialysis session. Diabetes was defined as a fasting blood glucose $\geq 126 \mathrm{mg} / \mathrm{dL}$, casual blood glucose $\geq 200 \mathrm{mg} / \mathrm{dL}, \mathrm{HbA} 1 \mathrm{c}(\mathrm{NGSP}) \geq 6.5 \%$, use of insulin, or use of oral hypoglycemic agents. History of cardiovascular disease (CVD) was defined as a history of heart failure requiring hospitalization, coronary artery disease requiring coronary artery intervention or heart bypass surgery, stroke, aortic disease requiring surgery, or peripheral artery disease requiring hospitalization. The period of nephrology care was established, based on patients' medical records, as the period from referral to the nephrologist until the initiation of dialysis. Medication use referred to the drugs taken at dialysis initiation. Blood tests were performed on samples taken before the first dialysis session. Blood pressure was measured before the first dialysis session.

\section{Group assignment according to serum adjusted calcium levels}

The serum calcium levels at dialysis initiation of patients with a serum albumin level $<4.0 \mathrm{~g} / \mathrm{dL}$ were adjusted employing the Payne formula. According to adjusted serum calcium levels, the patients were divided into the following 5 groups: (1) G1 with a serum adjusted calcium level $<7.0 \mathrm{mg} / \mathrm{dL}$, (2) $\mathrm{G} 2$ with 7.0 to $<8.0 \mathrm{mg} / \mathrm{dL}$, (3) G3 with 8.0 to $<9.0 \mathrm{mg} / \mathrm{dL}$, (4) G4 with 9.0 to $<10.0 \mathrm{mg} / \mathrm{dL}$, and (5) G5 with $\geq 10.0 \mathrm{mg} / \mathrm{dL}$.

\section{Assessment of aortic and cardiac valve calcification}

Aortic calcification was assessed according to the presence or absence of aortic arch calcification on plain frontal chest radiographs taken immediately before dialysis initiation. Cardiac valve calcification was assessed according to the presence or absence of a calcified aortic or mitral valve determined by B-mode echocardiography during the 1-month periods before and after dialysis initiation.

\section{Assessment of activities of daily living with the Barthel index}

The BI is composed of 10 items: (1) eating, (2) transferring between the bed and wheelchair, (3) grooming, (4) using the toilet, (5) bathing, (6) walking on a flat surface, (7) climbing and descending stairs, (8) dressing, (9) controlling bowel movements, and (10) controlling urination. Each item is evaluated on a 2-point ( 0 and 5$)$ to 4-point $(0,5,10$, and 15$)$ scale, and the total score $(0-100$ in increments of 5) is used for assessment [16]. In the present study, experienced nurses assessed the patients to determine the $\mathrm{BI}$ on discharge for dialysis initiation. 


\section{Survey of survival prognosis}

Survival prognosis as of March 31, 2015 was determined by surveying medical records. For patients who were transferred to other institutions, information was obtained by mailing out survey forms.

\section{Outcomes}

The study outcomes included (1) comparisons of allcause mortality rates in the five groups as categorized by serum adjusted calcium level; (2) extraction of factors, which included serum adjusted calcium, influencing allcause mortality.

\section{Statistical processing}

The easy R (EZR) was used for statistical processing

[17]. Comparisons of characteristics and baseline data between the five groups of patients were performed using the analysis of variance (ANOVA) for continuous variables and chi-square test for nominal variables. Allcause mortality rates were compared using the log-rank test for the Kaplan-Meier curves. Factors contributing to the all-cause mortality rates were examined using univariate Cox proportional hazard regression analysis. In addition to the serum adjusted calcium level, factors that were significant in the univariate analysis served as explanatory variables for the multivariate Cox proportional hazard analysis using the stepwise method (i.e., serum adjusted calcium, age, gender, BMI, SBP, DBP, CTR, history of CVD, use of calcium carbonate, hemoglobin, serum albumin, eGFR, PTH, and CRP). In stratified analyses, all-cause mortality rates were compared by Cox proportional hazard models adjusted for the factors used

Table 1 Patient characteristics at baseline by serum adjusted calcium levels

\begin{tabular}{|c|c|c|c|c|c|c|c|}
\hline Variables & $\begin{array}{l}\text { All } \\
n=1517\end{array}$ & $\begin{array}{l}\mathrm{G} 1 \\
n=114\end{array}$ & $\begin{array}{l}G 2 \\
n=241\end{array}$ & $\begin{array}{l}\mathrm{G} 3 \\
n=530\end{array}$ & $\begin{array}{l}\mathrm{G} 4 \\
n=522\end{array}$ & $\begin{array}{l}\mathrm{G} 5 \\
n=110\end{array}$ & $p$ trend \\
\hline Age (years old) & $67.5+13.1$ & $60.4+14.0$ & $63.8+13.4$ & $69.2+12.5$ & $68.8+12.7$ & $68.2+11.9$ & $<0.001$ \\
\hline Female gender $^{\mathrm{a}}$ & $491(32.4)$ & $43(37.7)$ & $61(25.3)$ & $167(31.5)$ & $176(33.7)$ & $44(40.0)$ & 0.033 \\
\hline $\mathrm{BMI}\left(\mathrm{kg} / \mathrm{m}^{2}\right)$ & $23.5+4.4$ & $23.5+4.2$ & $24.7+4.9$ & $23.5+4.4$ & $23.1+4.1$ & $23.1+4.4$ & $<0.001$ \\
\hline $\mathrm{SBP}(\mathrm{mmHg})$ & $151+26$ & $154+24$ & $154+28$ & $152+25$ & $150+26$ & $148+28$ & 0.129 \\
\hline $\mathrm{DBP}(\mathrm{mmHg})$ & $77+15$ & $82+14$ & $80+17$ & $77+15$ & $76+15$ & $74+15$ & $<0.001$ \\
\hline Diabetes Mellitus $^{a}$ & $774(51.0)$ & $39(34.2)$ & $125(51.9)$ & $275(51.9)$ & $275(52.7)$ & $60(54.5)$ & 0.007 \\
\hline Cancer-bearing & $93(6.1)$ & $5(4.4)$ & $16(6.6)$ & $32(6.0)$ & $32(6.1)$ & $8(7.3)$ & 0.914 \\
\hline History of CVD & $681(44.9)$ & $29(25.4)$ & $98(40.6)$ & $248(46.8)$ & $251(48.1)$ & $55(50.0)$ & $<0.001$ \\
\hline Barthel index score ${ }^{b}$ & $100(90-100)$ & $100(100-100)$ & $100(100-100)$ & $100(90-100)$ & $100(80-100)$ & $100(50-100)$ & $<0.001$ \\
\hline Use of ACEls or $\mathrm{ARBs}^{\mathrm{a}}$ & $913(60.2)$ & $64(56.1)$ & $146(60.6)$ & $323(60.9)$ & $315(60.3)$ & $65(59.1)$ & 0.896 \\
\hline Use of beta blockers ${ }^{a}$ & $525(34.6)$ & $32(28.1)$ & 89 (36.9) & $197(37.2)$ & $182(34.9)$ & $25(22.7)$ & 0.025 \\
\hline Use of VDRAs ${ }^{a}$ & $412(27.2)$ & $30(26.3)$ & $58(24.1)$ & $142(26.8)$ & $143(27.4)$ & $39(35.5)$ & 0.290 \\
\hline Use of calcium carbonate ${ }^{a}$ & $531(35.0)$ & $45(39.5)$ & $91(37.8)$ & $194(36.6)$ & $165(31.6)$ & $36(32.7)$ & 0.254 \\
\hline Use of thiazide ${ }^{a}$ & $347(22.9)$ & $18(15.8)$ & $62(25.7)$ & $134(25.3)$ & $109(20.9)$ & $24(21.8)$ & 0.117 \\
\hline Use of ESAs ${ }^{a}$ & $1303(85.9)$ & $92(80.7)$ & $203(84.2)$ & $476(89.8)$ & $449(86.0)$ & $83(75.5)$ & $<0.001$ \\
\hline Hemoglobin (g/dL) & $9.4+1.6$ & $8.8+1.8$ & $9.4+1.5$ & $9.5+1.5$ & $9.4+1.6$ & $9.4+1.4$ & 0.002 \\
\hline Serum albumin (g/dL) & $3.20+0.60$ & $3.44+0.45$ & $3.25+0.58$ & $3.29+0.54$ & $3.10+0.62$ & $2.89+0.67$ & $<0.001$ \\
\hline BUN (mg/dL) & $91.8+30.4$ & $105.3+34.3$ & $96.9+31.7$ & $90.7+27.5$ & $88.1+29.5$ & $89.1+36.0$ & $<0.001$ \\
\hline eGFR (ml/min/1.73 m2) & $5.44+2.22$ & $4.21+1.36$ & $4.92+1.95$ & $5.44+1.92$ & $5.77+2.28$ & $6.30+3.48$ & $<0.001$ \\
\hline Serum creatinine $(\mathrm{mg} / \mathrm{dL})$ & $8.98+3.22$ & $11.53+4.52$ & $9.97+3.21$ & $8.75+2.83$ & $8.35+2.73$ & $8.23+3.72$ & $<0.001$ \\
\hline Serum adjusted calcium (mg/dL) & $8.62+1.06$ & $6.37+0.52$ & $7.50+0.29$ & $8.51+0.28$ & $9.34+0.27$ & $10.45+0.59$ & $<0.001$ \\
\hline Serum phosphorus (mg/dL) & $6.36+1.88$ & $7.89+2.24$ & $7.01+1.95$ & $6.22+1.62$ & $5.97+1.77$ & $5.97+1.92$ & $<0.001$ \\
\hline Alkaline phosphatase (IU/L) & $265+173$ & $291+137$ & $272+144$ & $260+164$ & $259+202$ & $265+155$ & 0.441 \\
\hline PTH $(\mathrm{pg} / \mathrm{mL})^{\mathrm{b}}$ & $292(186-432)$ & $440(329-625)$ & $375(274-518)$ & $307(208-429)$ & $231(147-360)$ & $150(71-230)$ & $<0.001$ \\
\hline CRP $(\mathrm{mg} / \mathrm{dl})^{\mathrm{b}}$ & $0.30(0.10-1.34)$ & $0.31(0.09-1.36)$ & $0.32(0.10-1.24)$ & $0.20(0.09-0.99)$ & $0.30(0.10-1.53)$ & $0.62(0.18-5.41)$ & $<0.001$ \\
\hline Duration of $\mathrm{NC}^{\mathrm{b}}$ & $588(160-1307)$ & $576(77-1226)$ & $579(195-1107)$ & $636(208-1295)$ & $573(132-1509)$ & $465(80-1161)$ & 0.517 \\
\hline
\end{tabular}

Mean $\pm \mathrm{SD},{ }^{\mathrm{a}}$ value (\%), ${ }^{\mathrm{b}}$ median (inter-quartile range)

$\mathrm{G} 1$ with a serum adjusted calcium level $<7.0 \mathrm{mg} / \mathrm{dL}$, G2 with 7.0 to $<8.0 \mathrm{mg} / \mathrm{dL}$, G3 with 8.0 to $<9.0 \mathrm{mg} / \mathrm{dL}$, G4 with 9.0 to $<10.0 \mathrm{mg} / \mathrm{dL}$, and G5 with $\geq 10.0 \mathrm{mg} / \mathrm{dL}$ $B M I$ body mass index, SBP systolic blood pressure, DBP diastolic blood pressure, CTR cardiothoracic rate, CVD cardiovascular disease, $A C E I$ angiotensin converting enzyme inhibitor, $A R B$ angiotensin-1 receptor blocker, VDRA vitamin D receptor activator, ESA erythropoiesis stimulating agent, $B U N$ blood urea nitrogen, eGFR estimated glomerular filtration rate, $P T H$ parathyroid hormone, CRP C reactive protein, NC nephrologist care 


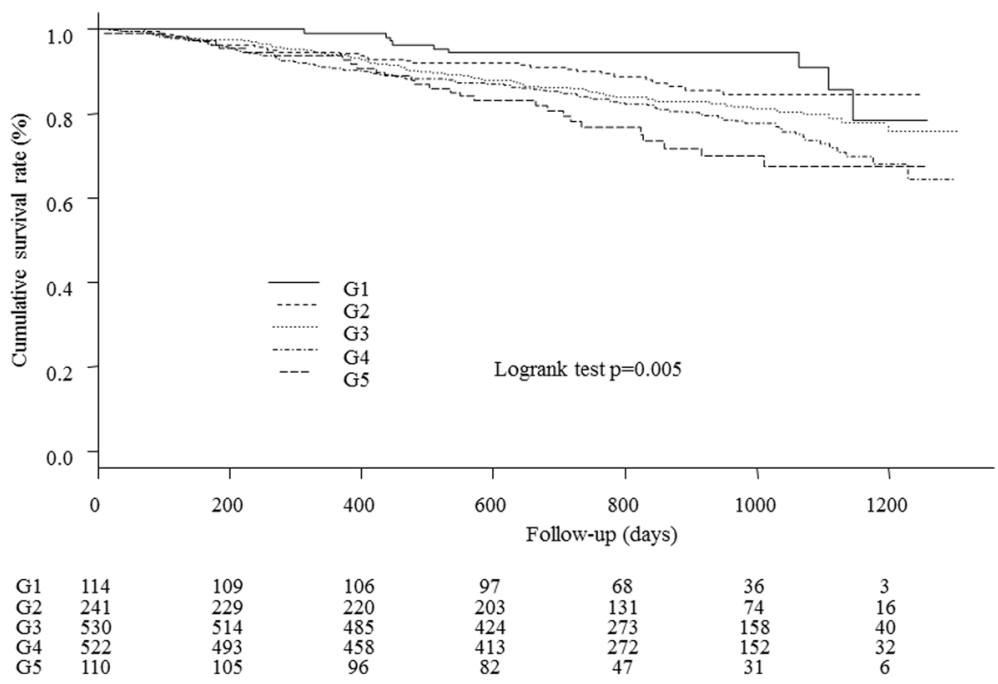

Fig. 1 Comparison of all-cause mortality among the five groups. Significant differences were observed between the five groups' cumulative survival rates $(p=0.005)$. G1 with a serum-adjusted calcium level $<7.0 \mathrm{mg} / \mathrm{dL}, \mathrm{G} 2$ with 7.0 to $<8.0 \mathrm{mg} / \mathrm{dL}$, G3 with 8.0 to $<9.0 \mathrm{mg} / \mathrm{dL}$, G4 with 9.0 to $<10.0 \mathrm{mg} / \mathrm{dL}$, and $\mathrm{G} 5$ with $\geq 10.0 \mathrm{mg} / \mathrm{dL}$ )

in the above-described step-wise analysis. Comparisons of aortic or cardiac valve calcification between the five groups of patient were performed using the chi-square test. Comparisons of Barthel index score between the five groups of patient were performed the analysis of variance (ANOVA). $P$ values less than $5 \%$ were considered statistically significant.

\section{Results}

\section{Comparison of patient characteristics and baseline data}

Table 1 shows the patient characteristics and baseline data in the five groups. Significant differences between the five groups were observed in age, gender, BMI, DBP, prevalence of diabetes mellitus, history of CVD, BI, rate of beta blockers use, rate of ESAs use, hemoglobin level, serum albumin level, blood urea nitrogen (BUN) level, eGFR, serum creatinine level, serum phosphorus level, serum PTH level, and C-reactive protein (CRP) level.

\section{Comparison of all-cause mortality}

Figure 1 shows Kaplan-Meier curves for the cumulative survival rates of the five groups. There were 268 deaths during the follow-up period (G1, 9 cases; G2, 30 cases; G3, 91 cases; G4, 110 cases; G5, 28 cases). Significant differences were observed between the five groups' cumulative survival rates $(p=0.005)$.

\section{Factors affecting all-cause mortality}

The results of univariate Cox proportional hazard regression analysis are presented in Table 2 . The increase in serum adjusted calcium levels was associated with the survival prognosis (every $1 \mathrm{mg} / \mathrm{dL}$ increase, hazard ratio $[\mathrm{HR}]=1.332,95 \%$ confidence interval $[\mathrm{CI}]=1.185-1.498$, $\mathrm{p}<0.001)$. In addition, high mortality was associated with advanced age, male gender, low BMI, low blood pressure, presence of cardiomegaly, history of CVD, no prior use of renin angiotensin system (RAS) inhibitors, no prior use of vitamin D receptor activator (VDRA), no prior use of calcium carbonate, no prior ESA use, presence of anemia, presence of hypoalbuminemia, high BUN level, high eGFR, low serum creatinine level, low serum phosphorus level, low PTH level, and high CRP level.

The results of multivariate Cox proportional hazard analysis using the stepwise method are shown in Table 3. Increasing serum adjusted calcium was associated with survival prognosis (every $1 \mathrm{mg} / \mathrm{dL}$ increase, $\mathrm{HR}=1.267$, 95\% $\mathrm{CI}=1.092-1.470, \quad p=0.002)$. In addition, high mortality was associated with advanced age, male gender, low systolic blood pressure, history of CVD, and no prior use of calcium carbonate.

\section{Association of serum adjusted calcium levels with aortic and cardiac valve calcification}

The five groups based on serum adjusted calcium levels at dialysis initiation were compared for aortic and cardiac valve calcification. There were significant differences in the incidence of either aortic or cardiac valve calcification among the five groups (aortic calcification $p=0.006$, cardiac valve calcification $p=0.008$ ) The incidence of calcification was especially low for G1 (Fig. 2).

\section{Association between serum adjusted calcium levels and the Barthel index}

BI scores were compared among the five groups based on serum adjusted calcium levels at dialysis initiation. 
Table 2 Associations of variables with all-cause mortality according to the univariate Cox proportional hazard regression analysis

\begin{tabular}{|c|c|c|c|}
\hline Variables & $\mathrm{HR}$ & $95 \% \mathrm{Cl}$ & $p$ value \\
\hline Serum adjusted calcium & 1.332 & $1.185-1.498$ & $<0.001$ \\
\hline Age & 1.057 & $1.045-1.070$ & $<0.001$ \\
\hline Female gender & 0.685 & $0.521-0.901$ & 0.007 \\
\hline BMI & 0.912 & $0.882-0.943$ & $<0.001$ \\
\hline $\mathrm{SBP}(/ 10 \mathrm{mmHg})$ & 0.922 & $0.892-0.953$ & $<0.001$ \\
\hline DBP $(/ 10 \mathrm{mmHg})$ & 0.837 & $0.789-0.888$ & $<0.001$ \\
\hline CTR & 1.034 & $1.017-1.051$ & $<0.001$ \\
\hline Diabetes Mellitus & 1.018 & $0.801-1.294$ & 0.882 \\
\hline History of CVD & 2.435 & $1.896-3.128$ & $<0.001$ \\
\hline Use of ACEls or ARBs & 0.732 & $0.576-0.931$ & 0.011 \\
\hline Use of beta blockers & 1.182 & $0.924-1.512$ & 0.183 \\
\hline Use of VDRAs & 0.708 & $0.529-0.949$ & 0.021 \\
\hline Use of calcium carbonate & 0.405 & $0.298-0.551$ & $<0.001$ \\
\hline Use of ESAs & 0.657 & $0.482-0.896$ & 0.008 \\
\hline Hemoglobin & 0.883 & $0.818-0.953$ & 0.001 \\
\hline Serum albumin & 0.642 & $0.529-0.779$ & $<0.001$ \\
\hline BUN (/10 mg/dL) & 1.041 & $1.004-1.080$ & 0.032 \\
\hline eGFR & 1.117 & $1.078-1.157$ & $<0.001$ \\
\hline Serum creatinine & 0.868 & $0.826-0.912$ & $<0.001$ \\
\hline Serum phosphorus & 0.927 & $0.865-0.993$ & 0.032 \\
\hline PTH (/10 pg/mL) & 0.994 & $0.988-0.999$ & 0.034 \\
\hline CRP & 1.036 & $1.017-1.056$ & $<0.001$ \\
\hline Duration of NC (/100 days) & 0.989 & $0.978-1.001$ & 0.066 \\
\hline
\end{tabular}

$B M I$ body mass index, SBP systolic blood pressure, DBP diastolic blood pressure, $C T R$ cardiothoracic rate, $C V D$ cardiovascular disease, $A C E l$ angiotensin converting enzyme inhibitor, $A R B$ angiotensin-1 receptor blocker, VDRA vitamin $D$ receptor activator, ESA erythropoiesis stimulating agent, $B U N$ blood urea nitrogen, eGFR estimated glomerular filtration rate, PTH parathyroid hormone, CRP C reactive protein, NC nephrologist care

Table 3 Associations of variables with all-cause mortality according to the multivariate Cox proportional hazard regression analysis using the stepwise method

\begin{tabular}{llll}
\hline Variables & HR & $95 \% \mathrm{Cl}$ & $P$ value \\
\hline Serum adjusted calcium & 1.267 & $1.092-1.470$ & 0.002 \\
Age & 1.045 & $1.030-1.060$ & $<0.001$ \\
Female gender & 0.656 & $0.471-0.912$ & 0.012 \\
SBP $(/ 10 \mathrm{mmHg})$ & 0.918 & $0.877-0.960$ & $<0.001$ \\
History of CVD & 1.656 & $1.229-2.231$ & $<0.001$ \\
Use of calcium carbonate & 0.580 & $0.409-0.822$ & 0.002
\end{tabular}

Adjusted for serum adjusted calcium, age, gender, BMI, SBP, DBP, CTR, history of CVD, use of calcium carbonate, hemoglobin, serum albumin, eGFR, PTH, and CRP

$B M I$ body mass index, SBP systolic blood pressure, $D B P$ diastolic blood pressure, CTR cardiothoracic rate, CVD cardiovascular disease, eGFR estimated glomerular filtration rate, $P T H$ parathyroid hormone, CRP C reactive protein
Lower BI scores were associated with higher serum adjusted calcium levels $(p<0.001)$ (Fig. 3).

\section{Stratified analysis}

The association between serum adjusted calcium levels and all-cause mortality was assessed with stratification by age, gender, history of CVD, BI score, VDRA use, calcium carbonate use, eGFR, and the PTH level. A significant association between serum adjusted calcium levels and all-cause mortality was observed in male patients age 70 years and older, a history of CVD, the full score of BI, VDRA use, no prior use of calcium carbonate, and an eGFR $\geq 5 \mathrm{~mL} / \mathrm{min} / 1.73 \mathrm{~m}^{2}$ (Fig. 4).

\section{Discussion}

The present results revealed serum adjusted calcium levels at dialysis initiation to be associated with all-cause mortality after dialysis initiation. Moreover, multivariate analysis identified a high serum adjusted calcium level as an independent risk factor for poor survival prognosis. Severe hypocalcemia is highly likely to occur during the early period after dialysis initiation. On the other hand, we found that high serum adjusted calcium levels were associated with poor outcomes. In other words, pathological conditions that inhibit the decrease in serum adjusted calcium levels might have been associated with poor survival prognosis.

We considered that renal function at dialysis initiation influenced serum adjusted calcium levels. As the glomerular filtration rate (GFR) decreases, serum phosphorus and fibroblast growth factor 23 levels increase, followed by a decrease in the serum activated vitamin $\mathrm{D}$ level. As a consequence, the serum calcium level decreases. Thus, if dialysis is initiated in patients with a high GFR, their serum calcium may still be elevated. Regarding the association between renal function at dialysis initiation and survival prognosis, there is reports describing the survival prognosis as being rather poor when dialysis is initiated in patients with a high eGFR [18, 19]. This is considered to be attributable to many patients who begin dialysis in the early stage being elderly, and also to early initiation of dialysis being inevitable in some patients because of concurrent CVDs. The present study also showed higher adjusted serum calcium levels at dialysis initiation to be associated with higher eGFR, more advanced age, and/or a greater likelihood of concurrent CVDs. Because stratified analysis by eGFR revealed high serum adjusted calcium levels to be associated with poor survival prognosis, regardless of renal function level at dialysis initiation, higher serum adjusted calcium levels with respect to renal function might be a clinical issue. Common causes of hypercalcemia include (1) hyperparathyroidism, (2) malignancy, (3) chronic granulomatous disease, (4) drugs (e.g., activated vitamin D preparations, 

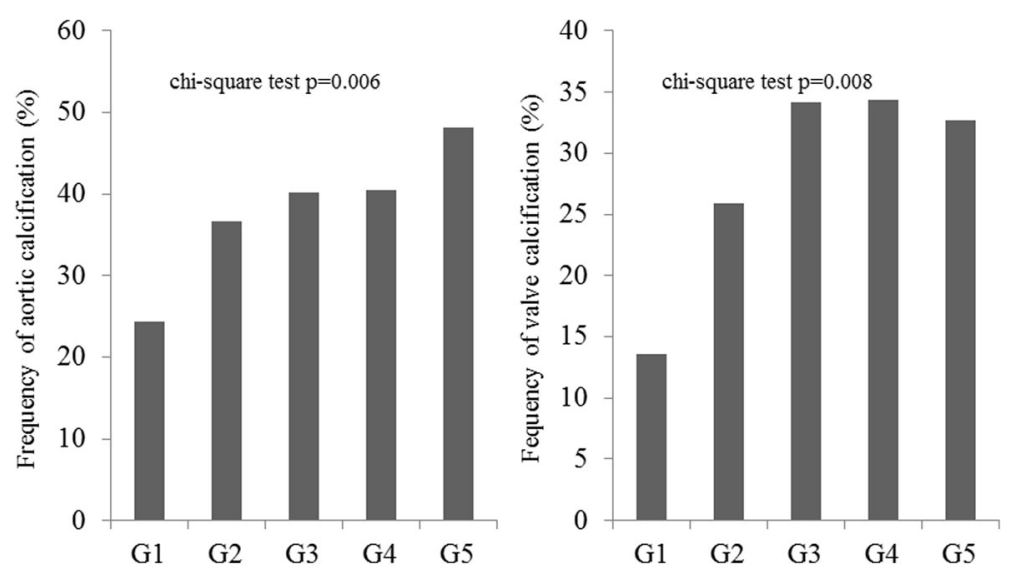

Fig. 2 Comparison of aortic and cardiac valve calcification among the five groups. Significant differences were observed between the five groups' frequency of aortic and cardiac valve calcification ( $p=0.006$ and $p=0.008$ ). G1 with a serum adjusted calcium level $<7.0 \mathrm{mg} / \mathrm{dL}, \mathrm{G} 2 \mathrm{with} 7.0$ to $<8.0 \mathrm{mg} / \mathrm{dL}$, G3 with 8.0 to $<9.0 \mathrm{mg} / \mathrm{dL}$, G4 with 9.0 to $<10.0 \mathrm{mg} / \mathrm{dL}$, and G5 with $\geq 10.0 \mathrm{mg} / \mathrm{dL}$

thiazide diuretics, and teriparatide), (5) hyperthyroidism, (6) adrenal insufficiency, (7) immobility, (8) total parenteral nutrition, and (9) milk-alkali syndrome [20]. We considered that among above causes of hypercalcemia, drugs or immobility led to increase in serum adjusted calcium level inconsistent with renal function. Because many reports have recently indicated that the use of calcium-containing phosphate binders in patients with dialysis worsens survival prognosis [21-23], we additionally examined drugs affecting serum calcium levels. The rate of using thiazide diuretics, VDRA, or calciumcontaining phosphate binders did not differ significantly among the groups. After the patients were stratified based on the use of VDRA or calcium-containing phosphate binders, the effects of these drugs on survival prognosis were assessed. Regardless of the use of these drugs, high serum adjusted calcium levels were generally associated with poor survival prognosis. Thus, when these serum calcium-elevating drugs are used, it would apparently be important to maintain the serum adjusted calcium concentration at "a level commensurate with renal function". The use of calcium carbonate was unexpectedly associated with better prognosis in the present study. Comparison of serum adjusted calcium and phosphorus levels between use and no use of calcium carbonate groups showed no significant differences (Additional file 1: Figure S1). In other word, patients who took more amount of phosphorus intake were likely administered calcium carbonate. We suspected that those of patients probably took sufficient dietary protein

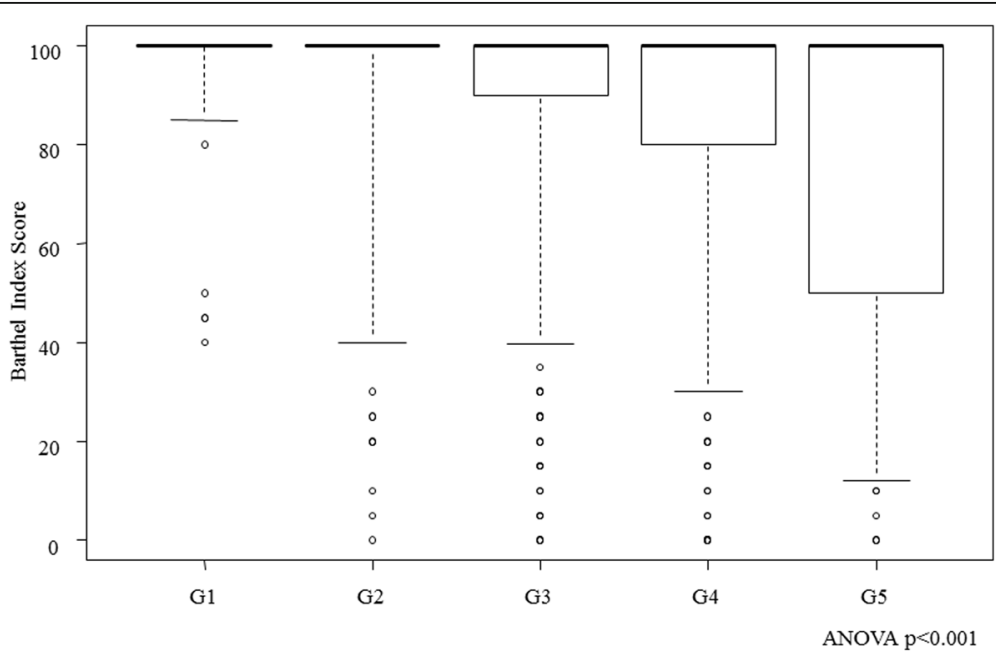

Fig. 3 Comparison of Barthel index score among the five groups. Significant differences were observed between the five groups' Barthel index score $(p<0.001)$. G1 with a serum adjusted calcium level $<7.0 \mathrm{mg} / \mathrm{dL}, \mathrm{G} 2$ with 7.0 to $<8.0 \mathrm{mg} / \mathrm{dL}, \mathrm{G} 3$ with 8.0 to $<9.0 \mathrm{mg} / \mathrm{dL}$, G4 with 9.0 to $<10.0 \mathrm{mg} / \mathrm{dL}$, and $\mathrm{G} 5$ with $\geq 10.0 \mathrm{mg} / \mathrm{dL}$. ANOVA, analysis of variance 


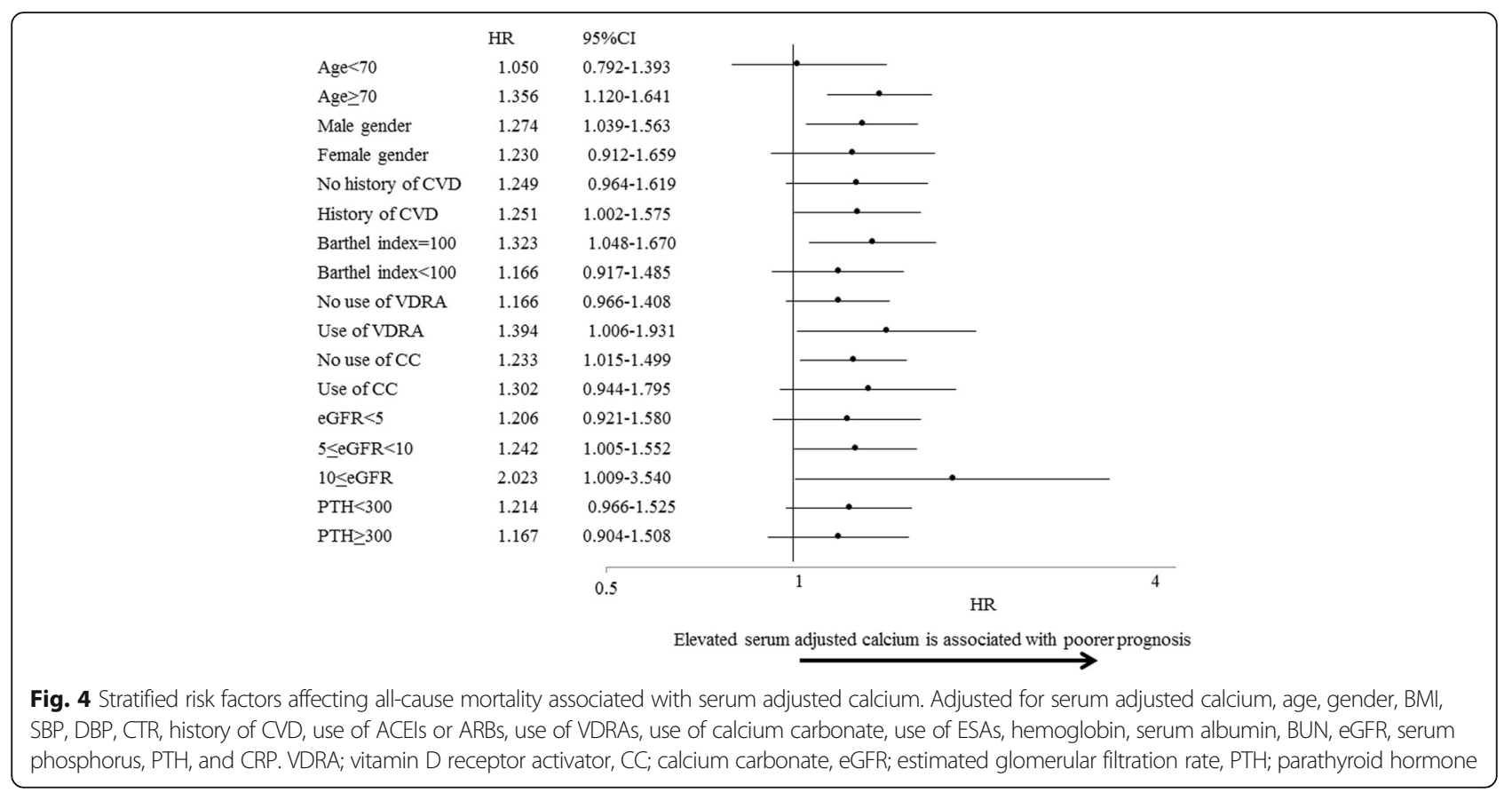

after dialysis initiation. Therefore, good nutritional status led to better prognosis during the relatively short term follow up period.

In the present study, patients with a high serum adjusted calcium level at dialysis initiation included many elderly as well as those with a low BI score, which reflects ADL. Thus, increased serum calcium levels due to immobility, one of the above-described causes of hypercalcemia, might have contributed to our results. Immobility promotes bone resorption via mobilization of calcium from bone, which in turn causes hypercalcemia [24, 25]. Consequently, PTH levels are suppressed. In the present study, PTH levels decreased as serum adjusted calcium levels rose. This result appears to be consistent with the known effects of immobility.

Elevated serum calcium is known to be a factor promoting vascular calcification [26]. Moreover, vascular calcification is an important pathological condition that affects survival prognosis [27]. The results of the present study revealed the prevalence of aortic and cardiac valve calcification to be higher in patients with higher serumadjusted calcium levels. This suggests that the poor survival prognosis in patients with higher serum adjusted calcium levels might be attributable to advanced organ dysfunction due to vascular calcification. However, it is also possible that such ectopic calcification is strongly associated with age-related factors.

The present study has the following limitations. First, because of the observational study design, there were differences in patient characteristics and baseline data among the groups, although the data were adjusted for several of these factors. We could not exclude the bias because several factors including age, gender, BMI, diabetes, and history of CVD were strongly associated mortality in general. Second, there was difference in the number of patients among the five groups. Hence, we conducted comparison of all-cause mortality between five groups classified by quintile of serum adjusted calcium. We considered that the bias was at minimum because the results were similar (Additional file 2: Figure S2). Third, the extent to which low BI scores reflect bone resorption due to immobility is unknown. The subjects of the present study were limited to patients who could be discharged to home or transferred to another facility after dialysis initiation. Thus, there were only a few patients with very low $\mathrm{ADL}$ who were bedridden $24 \mathrm{~h}$ a day. In this situation, it is not certain whether the physical activity levels of the patients can be regarded as "immobility." Fourth, neither vascular nor cardiac valve calcification was assessed quantitatively. As the severity calcification was not considered, i.e., cases with mild to severe calcifications were handled equally in performing the analyses, this study lacks sufficient objectivity to identify calcification as a cause of poor prognosis.

\section{Conclusions}

Serum-adjusted calcium levels at dialysis initiation were demonstrated to be associated with all-cause mortality after dialysis initiation. 


\section{Additional files}

Additional file 1: Figure S1. Comparison of serum adjusted calcium and phosphorus level between use and no use of calcium carbonate groups. No significant differences were observed between the two groups' serum mineral levels ( $p=0.071$ and $p=0.634$ ) by $t$ test. (TIF $40 \mathrm{~kb}$ )

Additional file 2: Figure S2. Comparison of all-cause mortality among the five groups classified by quintile of serum adjusted calcium. Significant differences were observed between the five groups' cumulative survival rates $(p<0.001)$. Q1 with the lowest serum adjusted calcium level, Q5 with the highest serum adjusted calcium level. (TIF $42 \mathrm{~kb}$ )

\section{Acknowledgements}

We acknowledge the support provided by the following investigators and members of the Aichi Cohort study of Prognosis in Patients Newly Initiated Into Dialysis (AICOPP), who participated in this study: Akihito Tanaka, Minako Murata, Hibiki Shinjo, Yasuhiro Otsuka, Asami Takeda (Japanese Red Cross Nagoya Daini Hospital), Hirofumi Tamai (Anjo Kosei Hospital), Tomohiko Naruse (Kasugai Municipal Hospital), Kei Kurata (Tosei General Hospital), Hideto Oishi (Komaki City Hospital), Isao Aoyama (Japanese Community Healthcare Organization Chukyo Hospital), Hiroshi Ogawa (Shinseikai Daiichi Hospital), Hiroko Kushimoto (Chita City Hospital), Hideaki Shimizu (Chubu-Rosai Hospital), Junichiro Yamamoto (Tsushima City Hospital), Hisashi Kurata (Toyota Kosei Hospital), Taishi Yamakawa (Toyohashi Municipal Hospital), Takaaki Yaomura (Nagoya Medical Center), Hirotake Kasuga (Nagoya Kyouritsu Hospital), Shizunori Ichida (Japanese Red Cross Nagoya Daiichi Hospital), Shoichi Maruyama (Nagoya University Graduate School of Medicine), Seiichi Matsuo (Nagoya University Graduate School of Medicine), and Noritoshi Kato (Nagoya University Graduate School of Medicine).

\section{Funding}

Not applicable.

\section{Availability of data and materials}

Not applicable.

\section{Authors' contributions}

$\mathrm{DI}$ participated in the design of the study and interpretation of the data. DI SK, and $\mathrm{HH}$ participated in writing the manuscript. All authors were involved in drafting, reviewing, and approving the final manuscript.

\section{Competing interests}

The authors declare that they have no competing interests.

\section{Consent for publication}

Not applicable.

\section{Ethics approval and consent to participate}

This study was conducted by following the Ethical guidelines for Clinical Research by the Japanese Ministry of Health, Labor, and Welfare (created July 30, 2003; full revision December 28, 2004; full revision July 31, 2008) and the Helsinki Declaration (revised 2013) and was approved by the clinical research ethics committees at each AICOPP group facility (the approval number: 20110823-3). The subjects received oral and written explanations of the purpose of the study and provided their consent in writing.

Received: 23 July 2016 Accepted: 8 December 2016 Published online: 30 January 2017

\section{References}

1. Kidney Disease: Improving Global Outcomes (KDIGO) CKD-MBD Work Group. KDIGO clinical practice guideline for the diagnosis, evaluation, prevention, and treatment of Chronic Kidney Disease-Mineral and Bone Disorder (CKD-MBD). Kidney Int Suppl. 2009;113:S1-130.

2. Block GA, Klassen PS, Lazarus JM, Ofsthun N, Lowrie EG, Chertow GM. Mineral metabolism, mortality, and morbidity in maintenance hemodialysis. J Am Soc Nephrol. 2004;15(8):2208-18.

3. Stevens LA, Djurdjev O, Cardew S, Cameron EC, Levin A. Calcium, phosphate, and parathyroid hormone levels in combination and as a function of dialysis duration predict mortality: evidence for the complexity of the association between mineral metabolism and outcomes. J Am Soc Nephrol. 2004:15(3):770-9.

4. Taniguchi M, Fukagawa M, Fujii N, Hamano T, Shoji T, Yokoyama K, Nakai S, Shigematsu T, Iseki K, Tsubakihara Y, Committee of Renal Data Registry of the Japanese Society for Dialysis Therapy. Serum phosphate and calcium should be primarily and consistently controlled in prevalent hemodialysis patients. Ther Apher Dial. 2013;17(2):221-8.

5. Kalantar-Zadeh K, Kuwae N, Regidor DL, Kovesdy CP, Kilpatrick RD, Shinaberger CS, McAllister CJ, Budoff MJ, Salusky IB, Kopple JD. Survival predictability of time-varying indicators of bone disease in maintenance hemodialysis patients. Kidney Int. 2006;70(4):771-80.

6. Floege J, Kim J, Ireland E, Chazot C, Drueke T, de Francisco A, Kronenberg F, Marcelli D, Passlick-Deetjen J, Schernthaner G, Fouqueray B, Wheeler DC, ARO Investigators. Serum iPTH, calcium and phosphate, and the risk of mortality in a European hemodialysis population. Nephrol Dial Transplant. 2011;26(6):1948-55.

7. Tentori F, Blayney MJ, Albert JM, Gillespie BW, Kerr PG, Bommer J, Young EW, Akizawa T, Akiba T, Pisoni RL, Robinson BM, Port FK. Mortality risk for dialysis patients with different levels of serum calcium, phosphorus, and PTH: the Dialysis Outcomes and Practice Patterns Study (DOPPS). Am J Kidney Dis. 2008:52(3):519-30.

8. Lin YC, Lin YC, Hsu CY, Kao CC, Chang FC, Chen TW, Chen HH, Hsu CC, Wu MS, Taiwan Society of Nephrology. Effect Modifying Role of Serum Calcium on Mortality-Predictability of PTH and Alkaline Phosphatase in Hemodialysis Patients: An Investigation Using Data from the Taiwan Renal Registry Data System from 2005 to 2012. PLoS One. 2015;10(6):e0129737.

9. Fukagawa M, Yokoyama K, Koiwa F, Taniguchi M, Shoji T, Kazama J J, Komaba H, Ando R, Kakuta T, Fujii H, Nakayama M, Shibagaki Y, Fukumoto S, Fujii N, Hattori M, Ashida A, Iseki K, Shigematsu T, Tsukamoto Y, Tsubakihara Y, Tomo T, Hirakata H, Akizawa T, CKD-MBD Guideline Working Group; Japanese Society for Dialysis Therapy. Clinical practice guideline for the management of chronic kidney disease-mineral and bone disorder. Ther Apher Dial. 2013;17(3):247-88.

10. Moldovan D, Rusu C, Kacso IM, Potra A, Patiu IM, Gherman-Caprioara M. Mineral and bone disorders, morbidity and mortality in end-stage renal failure patients on chronic dialysis. Clujul Med. 2016;89(1):94-103.

11. Chen NX, Moe SM. Pathophysiology of Vascular Calcification. Curr Osteoporos Rep. 2015;13(6):372-80.

12. Ossareh S. Vascular calcification in chronic kidney disease: mechanisms and clinical implications. Iran J Kidney Dis. 2011;5(5):285-99.

13. Hutchison AJ. Predialysis management of divalent ion metabolism. Kidney Int Suppl. 1999;73:S82-4

14. Doi T, Yamamoto S, Morinaga T, Sada KE, Kurita N, Onishi Y. Risk Score to Predict 1-Year Mortality after Hemodialysis Initiation in Patients with Stage 5 Chronic Kidney Disease under Predialysis Nephrology Care. PLoS One. 2015:10(6):e0129180

15. Hishida M, Tamai H, Morinaga T, Maekawa M, Aoki T, Tomida H, Komatsu S, Kamiya T, Maruyama S, Matsuo S, Inaguma D. Aichi cohort study of the prognosis in patients newly initiated into dialysis (AICOPP): baseline characteristics and trends observed in diabetic nephropathy. Clin Exp Nephrol. 2016 Feb 23. [Epub ahead of print]

16. Mahoney Fl, Barthel DW. Functional Evaluation: The Barthel Index. Md State Med J. 1965;14:61-5.

17. Kanda Y. Investigation of the freely available easy-to-use software 'EZR' for medical statistics. Bone Marrow Transplant. 2013;48(3):452-8.

18. Hwang SJ, Yang WC, Lin MY, Mau LW, Chen HC, Taiwan Society of Nephrology. Impact of the clinical conditions at dialysis initiation on mortality in incident hemodialysis patients: a national cohort study in Taiwan. Nephrol Dial Transplant. 2010:25(8):2616-24.

19. Rosansky SJ, Eggers P, Jackson K, Glassock R, Clark WF. Early start of hemodialysis may be harmful. Arch Intern Med. 2011:171(5):396-403.

20. Khairallah W, Fawaz A, Brown EM, El-Hajj FG. Hypercalcemia and diabetes insipidus in a patient previously treated with lithium. Nat Clin Pract Nephrol. 2007;3(7):397-404

21. Borzecki AM, Lee A, Wang SW, Brenner L, Kazis LE. Survival in end stage renal disease: calcium carbonate vs. sevelamer. J Clin Pharm Ther 2007:32(6):617-24.

22. Block GA, Raggi P, Bellasi A, Kooienga L, Spiegel DM. Mortality effect of coronary calcification and phosphate binder choice in incident hemodialysis patients. Kidney Int. 2007;71(5):438-41. 
23. Jamal SA, Vandermeer B, Raggi P, Mendelssohn DC, Chatterley T, Dorgan M, Lok CE, Fitchett D, Tsuyuki RT. Effect of calcium-based versus non-calciumbased phosphate binders on mortality in patients with chronic kidney disease: an updated systematic review and meta-analysis. Lancet. 2013;382(9900):1268-77.

24. Stewart AF, Adler M, Byers CM, Segre GV, Broadus AE. Calcium homeostasis in immobilization: an example of resorptive hypercalciuria. N Engl J Med. 1982;306(19):1136-40.

25. Alborzi F, Leibowitz AB. Immobilization hypercalcemia in critical illness following bariatric surgery. Obes Surg. 2002;12(6):871-3.

26. Razzaque MS. The dualistic role of vitamin $D$ in vascular calcifications. Kidney Int. 2011;79(7):708-14

27. Blacher J, Guerin AP, Pannier B, Marchais SJ, London GM. Arterial calcifications, arterial stiffness, and cardiovascular risk in end-stage renal disease. Hypertension. 2001;38(4):938-42.

Submit your next manuscript to BioMed Central and we will help you at every step:

- We accept pre-submission inquiries

- Our selector tool helps you to find the most relevant journal

- We provide round the clock customer support

- Convenient online submission

- Thorough peer review

- Inclusion in PubMed and all major indexing services

- Maximum visibility for your research

Submit your manuscript at www.biomedcentral.com/submit
Biomed Central 